\title{
Estudo da utilização de agregados de pneus inservíveis em concreto para aplicação em pisos intertravados
}

\section{Tyre aggregates use study unserviceable concrete floors for application interlocked}

\author{
1 Pedro Fernandes São Thiago pedrofthiago2007@gmail.com \\ 2 Luiz de Araujo Bicalho \\ 1 Mestrando em Materiais, Centro Universitário de Volta Redonda, UniFOA \\ 2 Docente do Mestrado em Materiais, Centro Universitário de Volta Redonda, UniFOA
}

\section{RESUMO}

A disposição final dos pneus inservíveis, no Brasil, e no mundo, é considerada uma questão pública, pois é discutida entre os ambientalistas, uma vez que são o meio ambiente e a sociedade os mais prejudicados. 0 acúmulo de resíduos sólidos na forma de pneus inservíveis cresce em grandes proporções, tornando-se necessário minimizar os prejuízos que causam. Dessa forma, é fundamental a implantação de projetos que envolvem reciclagem de resíduos sólidos, buscando uma solução em relação à problemática ambiental. É ainda de grande relevância, por ser uma oportunidade de se gerar empregos, evitar proliferação de doenças, além de contribuir com o meio ambiente com a sociedade e com a saúde pública. O presente estudo refere-se ao reaproveitamento de resíduos de borracha provenientes de pneus para produção de blocos de concreto ou simplesmente pavers, com desempenho satisfatório para atender a construção civil, de acordo com as normas de engenharia vigentes. $\mathrm{O}$ material picotado foi submetido a peneiramento, descartando-se os grãos de borracha de pneu abaixo de 0,60mm e os grãos acima de 2,00mm. Foram confeccionados corpos-de-prova com dosagens de borracha em $5 \%, 10 \%, 15 \%$ e $20 \%$ (em volume), conforme informações disponíveis na internet. Os corpos-de-prova foram submetidos a ensaio de compressão axial e absorção de água, obedecendo às normas NBR5739/2007 para compressão e NBR9778/2003 para absorção de água. Tais ensaios foram realizados nos laboratórios do Curso de Engenharia Civil e laboratórios de Materiais do Centro Universitário de Volta Redonda - UniFOA. Com isso verificou-se a possibilidade de aplicação das dosagens escolhidas. Teores de $10 \%$ e $15 \%$ de borracha mostraram-se suficientes à utilização dos pavers, como pisos intertravados para calçadas.

\section{Palavras-chave}

Pneus inservíveis. Reciclagem. Fabricação de pavers. Pisos intertravados.

\begin{abstract}
The final disposal of waste tires, in Brazil, and in the world, is considered a public issue, as it is discussed among environmentalists, since the environment and society are the most harmed. The accumulation of solid waste in the form of waste tires grows in large proportions, making it necessary to minimize the damage they cause. In this way, it is fundamental to implement projects involving solid waste recycling, seeking a solution in relation to environmental issues. It is also of great relevance, since it is an opportunity to generate jobs, to prevent the proliferation of diseases, and to contribute to the environment with society and public health. The present study refers to the reuse of rubber waste from tires for the production of concrete blocks or, simply 'pavers', with satisfactory performance to meet the civil construction, according to the current engineering standards. The perforated material was subjected to sieving, discarding the tire rubber grains below $0.60 \mathrm{~mm}$ and grains above $2.00 \mathrm{~mm}$. Test specimens with rubber dosages were made at $5 \%, 10 \%, 15 \%$ and $20 \%$ (by volume), according to information available on the internet. The test specimens were submitted to axial compression and water absorption tests, according to the NBR5739/ 2007 standards for compression and NBR9778 / 2003 for water absorption. These tests were carried out in the Laboratories of the Civil Engineering Course and Materials Laboratories of the University Center of Volta Redonda - UniFOA. With this, it was verified the possibility of applying the dosages chosen. $10 \%$ and $15 \%$ rubber contents were sufficient to use the pavers, such as interlocking floors for sidewalks.
\end{abstract}

\section{Keywords}

Scrap tires. Recycling. Manufacturing pavers. Interlocking floors.

\section{Como você deve citar?}

SÃO THIAGO, Pedro Fernandes; BICALHO, Luiz de Araujo. Estudo da utilização de agregados de pneus inservíveis em concreto para aplicação em pisos intertravados. Cadernos UniFOA, Volta Redonda, n. 36, p. 15-27, abr. 2018. 


\section{INTRODUÇÃO}

Para enfrentar os danos causados pelo impacto ambiental gerado pelos resíduos sólidos a partir da Revolução Industrial, decorrentes de uma inadequada disposição final, vêm sendo adotadas mundialmente, algumas formas de minimização que incluem o reuso e a reciclagem desses materiais, ação que tem como meta a diminuição da extração de recursos naturais, além de maximizar a vida útil dos aterros sanitários ${ }^{3}$.

Nesse contexto, se insere a questão dos pneus velhos ou inservíveis, que requer atenção especial, uma vez que, além de constituir um passivo ambiental, ocasiona sérios riscos ao meio ambiente e a saúde pública ${ }^{4}$.

Dessa forma, é possível buscar alternativas de disposição desses resíduos e modificação das propriedades do concreto para atendimento a requisitos específicos ligados às propriedades estruturais importantes em determinadas aplicações ${ }^{5}$.

Nesse sentido, por meio de ensaios de resistência mecânica à compressão e de absorção de água, avaliou-se quatro composições de agregados de farelo de pneus no traço do concreto.

Diante do exposto, o presente artigo teve como objetivo avaliar a viabilidade técnica de utilização dos pavers com incorporação de resíduos de pneus para uso em pisos intertravados, utilizando-se partículas de borrachas provenientes de pneus reciclados. Avaliou-se, de forma experimental, a incorporação desses resíduos ao produzir os pavers por meio de ensaios de resistência mecânica à compressão e absorção de água.

\section{RESÍDUOS}

Os resíduos se apresentam no estado sólido, semissólido ou líquido, sendo que alguns podem ser reciclados recebendo uma destinação ou um tratamento adequado. Tais resíduos são restos de atividades humanas, industriais considerados inservíveis ${ }^{6}$.

A Lei número 12305, de 02 de agosto de 2010, trata da Política Nacional de Resíduos Sólidos no Brasil, criada com a finalidade de encaminhar diretrizes relativas à gestão integrada e ao gerenciamento de resíduos sólidos, portanto, não há dúvidas em relação à relevância dessa lei? .

Os resíduos sólidos, como os pneus inservíveis, representam uma parcela dentre todos os resíduos gerados, que, quando mal gerenciados, provocam problemas ambientais, sanitários e sociais. Para que seja realizado o gerenciamento dos RS, torna-se necessário saber as fontes geradoras e os tipos de resíduos, buscando-se os elementos de sua composição como também o percentual de geração dele ${ }^{8}$.

\section{PNEUS INSERVÍVEIS}

De acordo com a NBR 10.004/1987, que trata da classificação dos resíduos sólidos, esse tipo de resíduo apresenta problemas ambientais em função de sua débil biodegradabilidade e alta combustibilidade, tornando-se um material de difícil controle após ser submetido ao fogo? .

Trata-se de um tipo de resíduo produzido pelas indústrias que, se destaca na discussão dos impactos sanitários e ambientais. Conforme dados da Associação Nacional da Indústria de Pneumático 
(ANIP, 2010), foram produzidos 67,3 milhões de unidades de pneus no Brasil, em 2010, com um crescimento de $15 \%$ em relação à produção de 2009 , porém, quando se tornam inservíveis, não são aproveitados devidamente ${ }^{10}$.

Parte desses pneus é coletada e direcionada para aterros sanitários, contribuindo para a redução da capacidade útil dos aterros. Esse resíduo favorece a proliferação de vetores de doenças, como o mosquito Aedes Aegypti, transmissor da dengue, quando descartados em outros locais impróprios. Existe ainda o risco de incêndio, com produção de fumaça tóxica constituída de $\mathrm{SO} 2$ (dióxido de enxofre), altamente poluidora, que pode também contaminar rios e lagos por liberar óleo em sua incineração"1.

\section{AS INDÚSTRIAS E OS RESÍDUOS SÓLIDOS}

Um dos tipos de resíduos que faz parte de discussões dos impactos ambientais é o pneu inservível, uma vez que alguns serviços de coleta depositam esse resíduo em aterros sanitários reduzindo sua capacidade útil, causando sua instabilidade e produzindo "ocos" na massa de resíduos"1.

Com o crescimento da indústria pneumática, tanto área de saúde quanto o meio ambiente, tem registrado sérios problemas, devido ao descarte dos pneus inservíveis ser realizado de forma inadequada, salientando-se ainda que há uma mistura de aço, tecidos, fibras e aditivos químicos, além da borracha ${ }^{8}$.

No Brasil, cerca de 100 milhões de pneus inservíveis são descartados de forma irregular no meio ambiente, conforme avaliação realizada pela Associação Nacional da Indústria de Pneumáticos (ANIP), o que demonstra que o descarte correto desses RS está longe de acontecer, devido à falta de conscientização da população, de apoio, de informações por parte do governo e uma fiscalização maior nas grandes empresas ${ }^{13}$.

Conforme a Resolução CONAMA ${ }^{4} \mathrm{n}^{\circ} 258$ de 26 de agosto de 1999, desde 2002 as indústrias pneumáticas do país e importadores estão obrigados a recolher parte dos pneus, entretanto o que se observa é que essa quantidade de produção tem crescido anualmente, chegando à proporção de cinco pneus inservíveis recolhidos para cada quatro pneus novos produzidos ou importados.

Uma das estratégias mais indicada para solucionar os problemas causados ao meio ambiente por esses resíduos, seria a reciclagem, que consiste em desenvolver novos produtos com os pneus inservíveis, resultando em uma destinação adequada a eles, gerando uma nova realidade econômica, o que implica à inclusão de um novo nicho comercial, gerando emprego e renda ${ }^{14}$.

\subsection{Reutilização e reciclagem dos pneus}

A reutilização e reciclagem dos pneus servíveis e inservíveis são: recapagem, recauchutagem, pavimentação com asfalto de borracha, utilização na construção civil, nas obras de contenção de encostas, solas de sapato, pisos esportivos, dentre outros ${ }^{15}$.

Os pneus inservíveis podem ser utilizados em obras de geotécnica, protegendo encostas, postes, docas de embarcações, dentre outras. Essa forma de utilização pode causar acúmulo de água em seu interior, devido à chuva e à forma pela qual são expostos. A reutilização de pneus inservíveis não foi avaliada quanto aos impactos ambientais negativos ${ }^{16}$.

A reciclagem de pneus inservíveis pode ser realizada no sistema à temperatura ambiente, em que os pneus são triturados, granulados e o aço removido por meio de uma esteira magnética. Devido 
à demanda por granulado de borracha, muitas empresas possuem um processo contínuo quanto à trituração desses resíduos, que podem ser utilizada para várias aplicações ${ }^{16}$.

Uma das aplicações do granulado de borracha é agregar esse resíduo ao fazer concreto, sendo uma solução relevante para a disposição indiscriminada desse passivo ambiental. 0 concreto, utilizando-se de borracha, possui características únicas, uma vez que os compostos de cimento apresentam facilidade em absorver resíduos sólidos industriais. Observa-se que inúmero órgão governamental e privado tem realizado pesquisas em busca de melhores formas na utilização desses resíduos, objetivando a redução de custos e mantendo a qualidade ${ }^{17}$.

Algumas alternativas de reciclagem seriam o reaproveitamento do pneu inservível em sua forma inteira, contribuindo para a questão da destinação final desse resíduo. Na Engenharia Civil, os pneus podem ser usados em sua forma inteira ou em partes. As aplicações mais usuais dos pneus inservíveis são em materiais de enchimento de peso leve, drenagem em campo séptico, aterro em estradas, suporte de base de estrada, sistema de drenagem de gases em aterros sanitários; material para compostagem, drenagem em aterro sanitário, aditivos para pavimentos asfálticos e pistas esportivas, dentre outros ${ }^{18}$.

\section{MATERIAIS E MÉTODOS}

Os materiais em estudo são compósitos constituídos por uma fase de matriz cerâmica - Cimento Portland (CP), uma fase dispersa composta por partículas de minerais e/ou partículas de borracha de pneus e água.

Foi realizado estudos em compósitos constituídos por uma fase de matriz cerâmica - Cimento Portland (CP), uma fase dispersa composta por partículas de minerais e/ou partículas de borracha de pneus e água.

Os Compósitos polímero-cerâmicos (CPC) são um grupo novo de materiais, cujas propriedades mecânicas e térmicas são muito significativas. São materiais resultantes da combinação de materiais cerâmicos e materiais poliméricos.

Para esta pesquisa, a Borracha de Pneu foi obtida de rejeitos de pneus velhos ou inservíveis oriundos do Centro de Picotagem da Cimpor - Jundiaí (SP). As partículas de borracha resultantes da picotagem dos pneus apresentam formatos e tamanhos diversos no material utilizado.

Traçou-se uma sequência de atividades, considerando as etapas, normas, documentações a levantar e trabalhos práticos a serem executados.

Para atingir os objetivos propostos, seguiu-se um Organograma (figura 1), no qual se definiu a ordem de eventos quanto à estrutura do projeto do compósito cimentício pretendido. 
Figura 1- Organograma do Projeto.

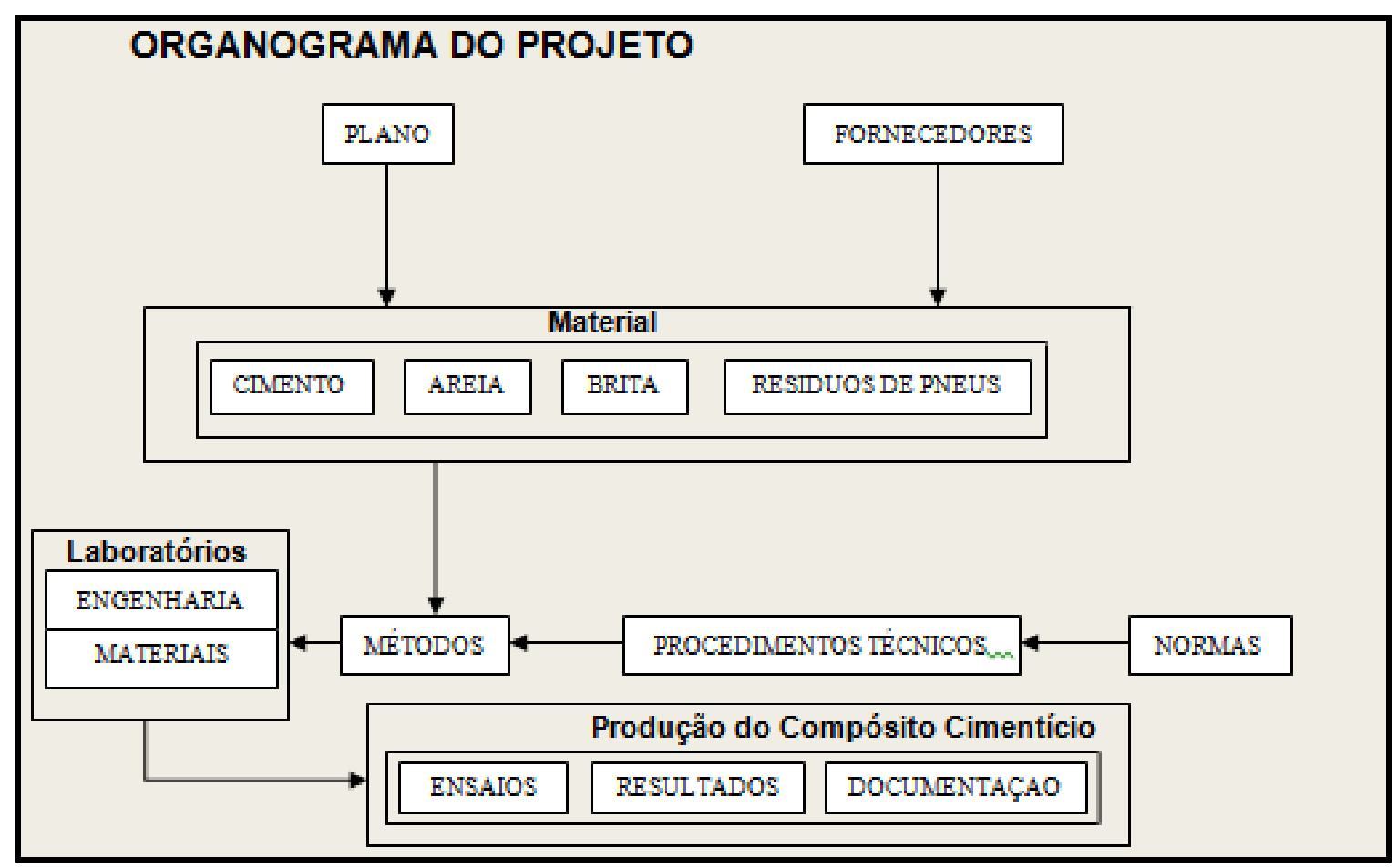

Fonte: dos autores, 2018

Para desenvolver a atividade, foi necessária a utilização de:

a. Brita - agregado graúdo: essas partículas foram fornecidas em faixas granulométricas comumente industrializadas. Para tanto, foram peneiradas e classificadas em faixas granulométricas, conforme previsto na norma ABNT NBR 7211:2009;

b. Areia - agregado miúdo: essas partículas foram fornecidas em faixas granulométricas comumente industrializadas;

c. Água: a produção do compósito pretendido neste trabalho foi utilizada água tratada e distribuída pela Companhia de abastecimento público SAAE - Serviço Autônomo de Água e Esgoto de Volta Redonda.

Todo o material foi peneirado para subsidiar a confecção do compósito cimentício. As partículas de borracha de pneus utilizadas no experimento possuíam uma composição granulométrica diversificada. Sendo assim, foram selecionados os grãos de borracha com tamanho menores que $2 \mathrm{~mm}$ (passante, undersize) e maiores que $600 \mu \mathrm{m}$ (retido, oversize) na malha das peneiras.

Em seguida, foram realizados alguns procedimentos de acordo com normas e procedimentos para ensaios da Associação Brasileira de Normas Técnicas - ABNT, para produção de compósito de concreto como: NBR 5738/2003 - Concreto: procedimento para moldagem e cura de corpos-de-prova e NBR 5739/2007 - Ensaio de compressão de corpos-de-prova cilíndricos.

Os ensaios foram desenvolvidos nos Laboratórios do Curso de Engenharia Civil e Laboratórios de Materiais (CIT) do Centro Universitário de Volta Redonda, UniFOA. Para a realização das atividades, foram utilizados alguns equipamentos, tais como: 
a. Betoneira: utilizada para misturar o concreto;

b. Copo Volumétrico de 1 litro: para adição da água;

c. Moldes Soloteste Cilíndricos $(\varnothing 10 \mathrm{~cm}$ de base $\times 20 \mathrm{~cm}$ de altura): para moldagem;

d. Barra de aço para compactação: para compactar o concreto do corpo-de-prova.

Foi misturada a areia, a brita e a borracha por cinco minutos na Betoneira, com $70 \%$ da água de amassamento. Feito isto, adicionou-se cimento à mistura e mais o restante da água por meio do Copo Volumétrico de 1 litro.

Para a moldagem e cura dos corpos-de-prova, foram necessários os seguintes passos:

Separação dos 12 Moldes de CPs;

- Oleamento dos CPs;

- Separação dos agregados;

- Mistura dos materiais na betoneira;

- Adição de água e Teste Slump;

- Enchimento e compactação dos CPs;

- Retirada dos CPs dos moldes e sua imersão no Tanque de Cura;

- A cada 7 dias: retirada de 3 CPs com 7,14, 21, 28 dd, para os testes de Compressão Axial.

Os moldes receberam fina camada de óleo mineral para facilitar a soltura dos CPs no ato da abertura dos moldes, para a retirada após a pré-cura de 24 h, conforme NBR 5738/2003.

O laboratório de Engenharia possui seu piso plano. Abrigou os CPs durante o período de pré-cura de 24h após o enchimento dos moldes com as misturas de concreto. Após esse período, os compósitos sofreram desmoldagem (Figura 2), foram identificados e transferidos direto para a câmara úmida e dispostos em posição vertical, imersos na água do tanque d'água. 
Figura 2- Fluxograma do processo.

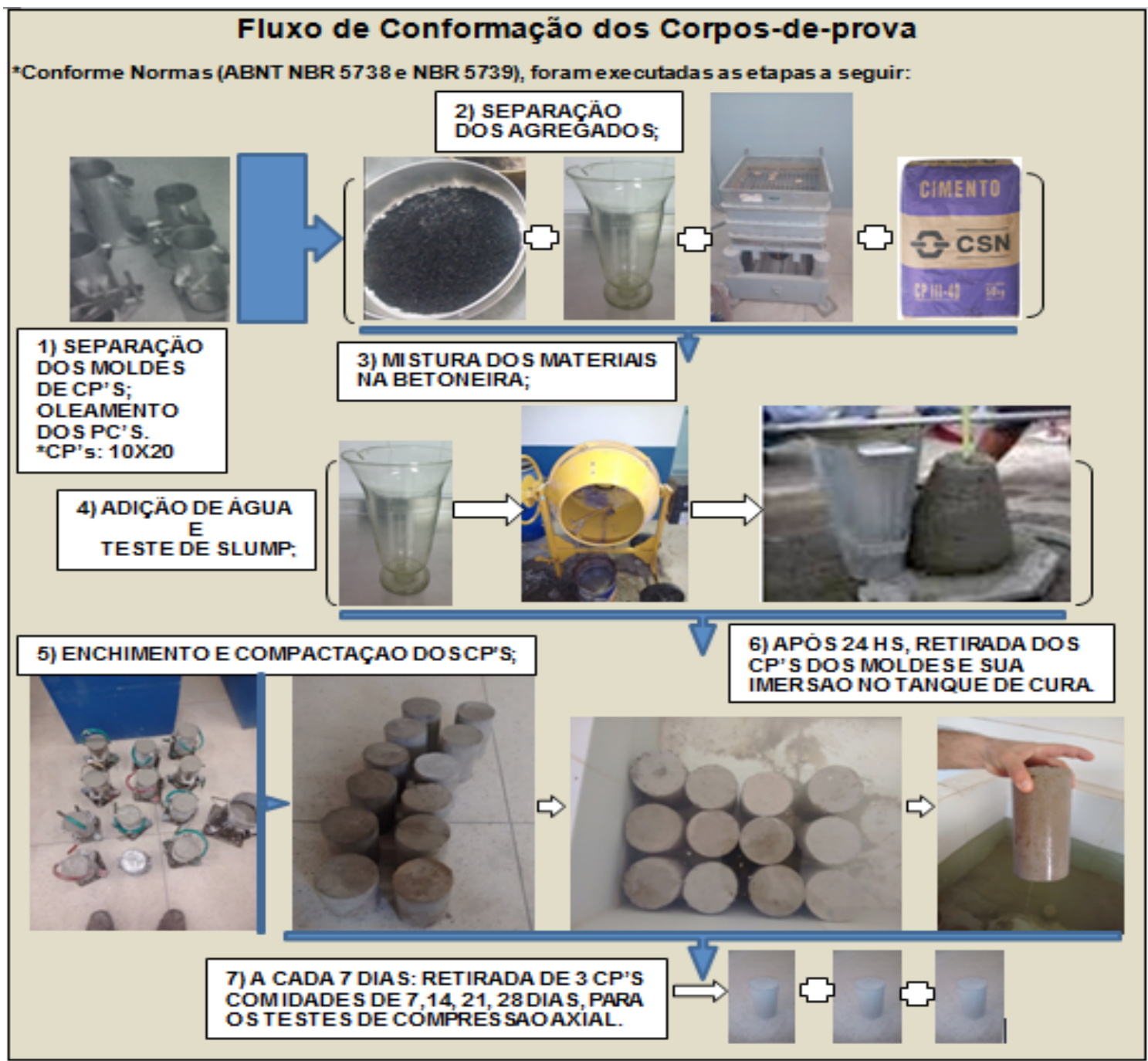

Fonte: dos autores, 2018.

\section{RESULTADOS E DISCUSSÕES}

\subsection{Resistência à compressão}

Foram feitos testes preliminares para escolher o nível das partículas de borracha, contendo diversas frações volumétricas, sendo que o limite máximo de $20 \%$ em volume de partículas de borracha foi verificado.

De acordo com a análise realizada nas tabelas 1, 2, 3, 4 e 5, foram observadas variações de resultados significativos, quando comparados corpos-de-prova com adição de resíduos de borracha com o corpo-de-prova de referência, revelando reações diferentes de comportamento.

Comparando-se os resultados obtidos entre o corpo-de-prova de referência e os corpos-de-prova com adição de resíduos de borracha, verificou-se que, aqueles CPs com adição de borracha, de forma geral, apresentaram valores de ensaio de resistência à compressão menores que o CP de referência, 
sendo que o percentual de $10 \%$ a $15 \%$ de resíduos a serem incorporados ao concreto dos CPs indicaram melhores resultados ao serem avaliados todos os ensaios de compressão.

Os dados obtidos nos ensaios de resistência à compressão e os resultados estão detalhados na tabela 1, de acordo com o nível de adição de resíduo borracha estabelecido previamente para os ensaios.

a. Caracterização do corpo-de-prova de referência: A tabela 1 apresenta os resultados referentes aos ensaios de compressão com os CPs de referência, ou seja, com $0 \%$ de adição de resíduos de borracha de pneu.

Tabela 1- Resistência à compressão da referência, após 28 dias.

\begin{tabular}{lll}
\hline $\begin{array}{l}\text { \% BORRACHA } \\
\text { ADICIONADA }\end{array}$ & TENSÃO MÉDIA (MPa) & Desvio padrão \\
\hline 0 & 24,53 & 1,074 \\
5 & 24,60 & 0,598 \\
10 & 19,76 & 1,533 \\
15 & 19,89 & 0,803 \\
20 & 12,66 & 0,370 \\
\hline
\end{tabular}

\subsection{Absorção de água}

Define-se a absorção de água de uma matéria pelo percentual de água absorvida por um corpo-de-prova depois da imersão em água sobre pressão negativa constante, conforme descrito na determinação da densidade e porosidade aparentes.

A expressão abaixo mostra a obtenção dessa variável-resposta.

$$
A_{b}=\frac{m_{2}-m_{1}}{m_{1}} \times 100
$$

Sendo: Ab é a absorção de água (\%); $\mathrm{m} 1$, peso seco; $\mathrm{m} 2$, peso molhado.

Ao comparar com o concreto de referência, verificou-se redução na densidade aparente. Observase que a densidade aparente, para as três composições de borracha ( $5 \%, 10 \%$ e $15 \%)$, sofre redução com o aumento do teor de borracha, como era de se esperar, pois a borracha é mais 'leve' que o concreto. As composições com adição de $15 \%$ e de $20 \%$ de borracha resultaram em CPs de consistência mecânica cada vez menor, sendo que os CPs de $20 \%$ de borracha foram descartados, pois, já na desmoldagem, mostravam-se inconsistentes. As variações de densidades real e aparente que ocorreram na composição de $15 \%$ de borracha fogem à expectativa, pois se esperava que fossem menores em relação aos que ocorreram para $10 \%$ de borracha. Esse fato poderia ser explicado pela desuniformidade de concentração do material no interior do CP. A porosidade externa do CP com 15\% de borracha foi evidentemente maior, fato este que pode ser justificado pela maior retenção de água, conforme dados obtidos na tabela 5. 
Tabela 5- Ensaio de absorção da agua nos CPs - $\left(\right.$ Volume Aparente $\left.=196,25 \mathrm{~cm}^{3}\right)$

\begin{tabular}{|c|c|c|c|c|c|}
\hline \multirow{2}{*}{$\begin{array}{l}\text { BORRACHA NO } \\
\text { CORPO-DE-PROVA } \\
(\%) \\
0\end{array}$} & \multirow{2}{*}{$\begin{array}{l}\text { DENSIDADE REAL } \\
2,87\end{array}$} & \multirow{2}{*}{$\begin{array}{l}\text { DENSIDADE } \\
\text { APARENTE } \\
\text { (a seco) } \\
2,22\end{array}$} & \multicolumn{2}{|c|}{$\begin{array}{l}\text { PESAGEM DO CORPO-DE- } \\
\text { PROVAS (gramas) }\end{array}$} & \multirow{2}{*}{$\begin{array}{l}\begin{array}{l}\text { RETENÇÃO D'ÁGUA } \\
(\%)\end{array} \\
10,06\end{array}$} \\
\hline & & & Seco & 437 & \\
\hline & & & Molhado & 481 & \\
\hline \multirow[t]{2}{*}{5} & 2,22 & 1,63 & Seco & 376 & 16,44 \\
\hline & & & Molhado & 422,28 & \\
\hline \multirow[t]{2}{*}{10} & 2,50 & 1,88 & Seco & 320 & 12,30 \\
\hline & & & Molhado & 372,61 & \\
\hline \multirow[t]{2}{*}{15} & 2,82 & 1,84 & Seco & 362 & 18,84 \\
\hline & & & Molhado & 430,23 & \\
\hline
\end{tabular}

Fonte: dos autores, 2018

Ao adicionar o resíduo de borracha em substituição às partículas minerais, observou-se que na fase de ensaios de resistência à compressão, houve um aumento da viscosidade do concreto, aumentando a porosidade, absorção de água, embora ocorresse pequena redução da resistência à compressão nos CPs.

\subsection{Microscopia Eletrônica de Varredura (MEV).}

A microscopia eletrônica de varredura (MEV) foi utilizada na análise microestrutural das superfícies das amostras, para verificação de adesão entre partículas e matriz. 0 equipamento utilizado para a obtenção das imagens foi o microscópio eletrônico de varredura Hitachi MEV-TM 3000, por meio de elétrons secundários com voltagem de aceleração de 15kV. Os corpos-de-prova fabricados para essa análise foram colocados em um porta amostra metálico.

As figuras 3, 4 e 5 exibem imagens de partículas de borracha, sendo possível identificar uma geometria angular de tamanho irregular, uma vez que é proveniente de processo de raspagem de pneus. $\mathrm{O}$ fragmento analisado foi extraído dos CPs após ensaio de compressão.

Ao analisar as figuras de números 3,4 e 5, embora a resistência à compressão não seja melhorada, nota-se maior absorção de água das misturas contendo borracha.

As figuras 3 e 4 mostram a borracha de pneu parcialmente encoberta pela matriz de cimento Portland, indicando bom potencial para utilização de borracha de pneus inservíveis.

A figura 5 apresenta a borracha de pneu envolvida pelo polímero. Essa matriz cimentícia demonstra aparência de melhor ligação entre a borracha de pneu e o concreto Portland. 
Figura 3- Imagem de partícula de borracha, com ampliação de 1000X.

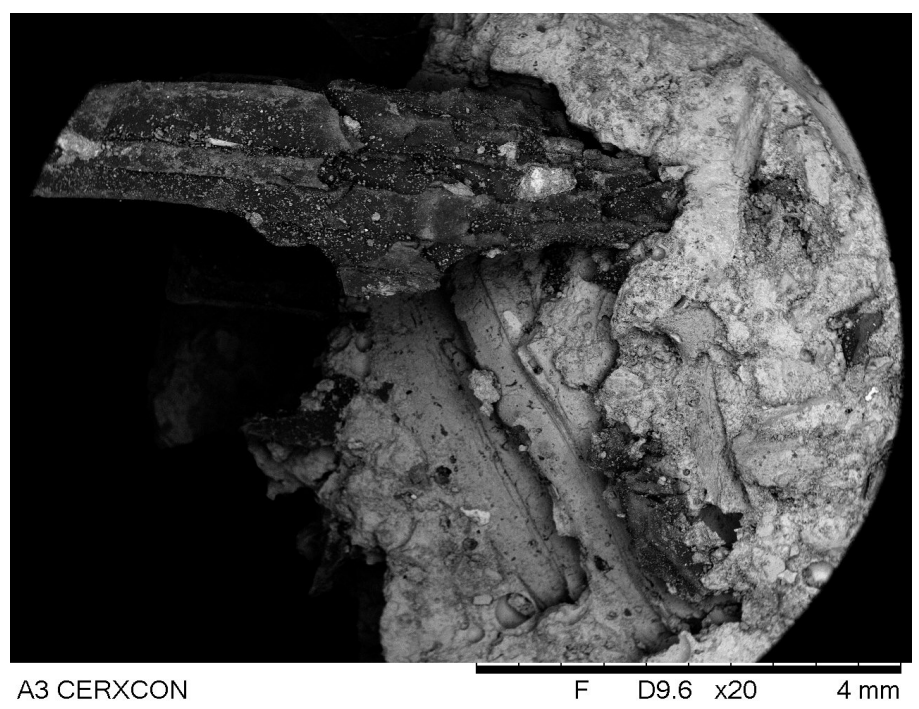

Fonte: dos autores, 2018

Figura 4- Imagem de partícula de borracha, com ampliação de 20X

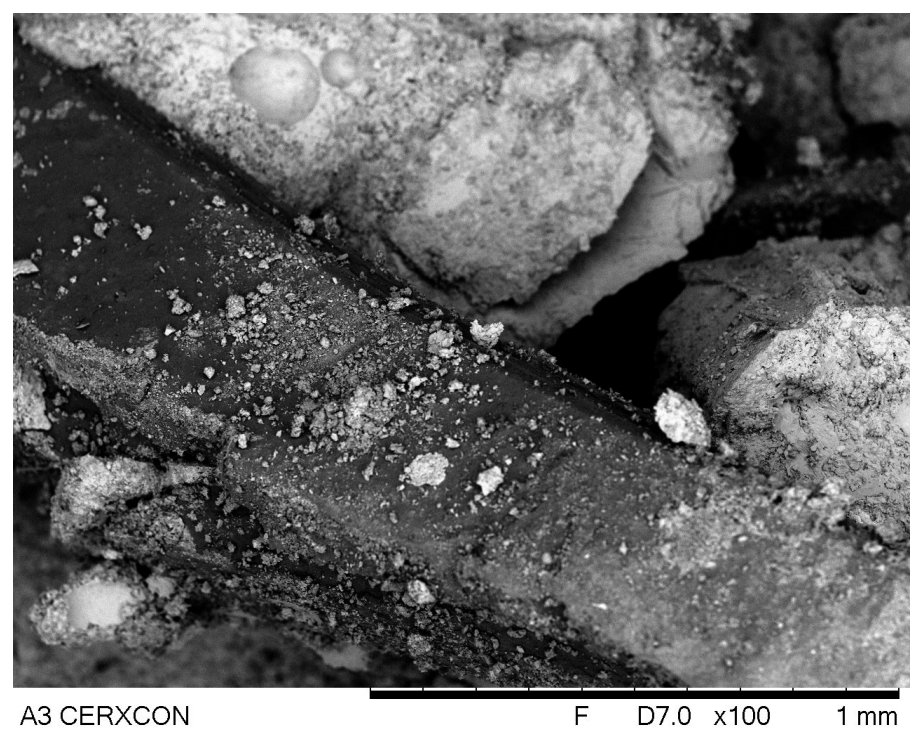

Fonte: dos autores, 2018. 
Figura 5- Imagem de partícula de borracha, com ampliação de 1000X.

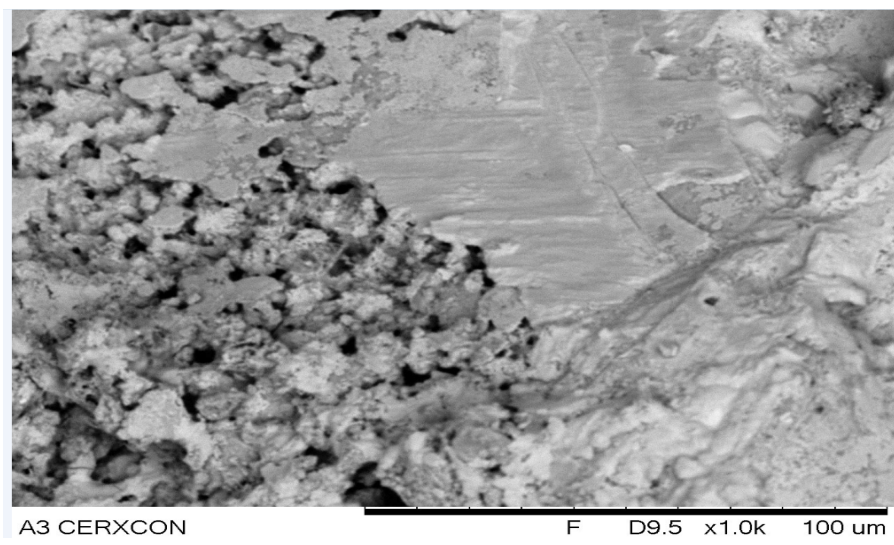

Fonte: dos autores, 2018

\section{CONCLUSÃO}

A realização deste trabalho permitiu observar que é possível utilizar resíduos de borracha, agregando-os a outros compósitos cimentícios, para produção de pavers.

Quanto ao estudo microestrutural do compósito, observou-se um aumento de formação de poros, ao se adicionar partículas de borracha, o que permite concluir que quanto maior o teor de borracha de pneus incorporado nos compósitos cimentícios, maior a redução das propriedades como densidade aparente e real, como também, menor a redução das propriedades como absorção de água e permeabilidade.

Dentre os traços em que se adicionou borracha granulada, os que apresentaram menores resultados, nos ensaios de resistência à compressão, foram os de $10 \%$ e $15 \%$ de adição de resíduos de pneus, ainda que tenha apresentado menores resistências, quando comparados com o concreto do corpo-de-prova de referência. Por isso, acredita-se que possa ser utilizado para construção de calçadas.

Apesar de o teor ideal de borracha, para algumas propriedades, esteja situado em torno de $5 \%$, o máximo de aproveitamento do resíduo de borracha de pneu na fabricação de pavers, sem prejudicar de forma considerável as propriedades mecânicas, fica em torno de $5 \%$ de partículas de borracha em substituição parcial do volume de areia.

A composição de $5 \%$ mostrou resistência à compressão similar à do concreto referência e de menos dispersão de resultados. Também se verificou que é ligeiramente melhor que a composição 10\%.

Em termos de absorção de água, a composição $5 \%$ foi melhor que o concreto referência e também superior à composição $10 \%$.

Os valores das características da composição 10\% não desautorizam suas aplicações, porque permitem maior aproveitamento dos resíduos de pneus inservíveis, mesmo que em utilizações menos nobres da engenharia civil.

Para tanto, todo esse processo utilizado na área da construção civil, contribui para redução de impactos ambientais, assim como para os problemas relacionados à saúde. 


\section{REFERÊNCIAS}

1 GUNTHER, W.M.R. Minimização de resíduos e educação ambiental. In: Seminário Nacional de Resíduos Sólidos e Limpeza Pública, 7. Curitiba, 2000. Anais. Curitiba, 2000.

2 MORAIS, N. S. Desenvolvimento Sustentável: Reciclagem de pneus. Cuiabá, 2009. Disponível em: <http://www.ebah.com.br/content/ABAAAAqZMAF/reciclagem-pneus>. Acesso em: 10 de maio 2012.

3 MOTTA, F. G. A. Cadeira de destinação de pneus inservíveis: o papel da regulação e do desenvolvimento tecnológico ambiente \& sociedade. V. XI, N. 1, P. 167 - 184. 2008.

4 BRASIL. Conselho Nacional do Meio Ambiente. Resolução n. 258 de 29 de abril de 2005. Determina que as empresas fabricantes e as importadoras de pneumáticos ficam obrigadas a coletar e dar destinação final ambientalmente adequada aos pneus inservíveis. Disponível em: < http:// www.mma.gov.br/port/ conama/res/res99/res25899.html>. Acesso em: 16 jan. 2015.

5 ZHOU,Y. Polymer-Ceramic Composites for Conformal Multilayer Antenna and RF Systems. Ph. D. dissertation. The Ohio State University, Columbus, Ohio.USA. 2009.

6 PEREIRA, L. C.; TOCCHETTO, M. R. L. Resíduos: É preciso inverter a pirâmide - reduzir a geração. .Disponível em: <http://www.ambientebrasil.com.br/composer.php3?base=residuos/index.php3.../ residuos.htm>. Acesso em: 28 set. 2014.

7 BRASIL. Lei n. 12305 de 02 de agosto de 2010. Institui a Política Nacional de Resíduos Sólidos. Diário Oficial. Brasília, 2010. Disponível em: <http://www.planalto.gov.br/ccivil_03/_ato2007-2010/2010/lei/ 112305.htm>. Acesso em: 26 ago. 2014.

$8 \mathrm{KGATHI}$, D.L. e BOLAANE, B. Instruments for sustainable solid waste management waste: management and research. 2002. Disponível em <http://www.deecc.ufc.br/download/gestao_de_residuos_solidos_ pgtga/consideracoes_s obre_residuos_solidos.pdf>. Acesso em: 1 ago. 2014.

9 ABNT. Associação Brasileira de Normas Técnicas. NBR 10004. Resíduos sólidos- Classificação. Rio de Janeiro. 2004.

10 ANIP. Associação Nacional da Indústria de Pneumáticos. Disponível em

< www.anip.com.br>. Acesso em: 08 jan. 2015.

11 IPT. Instituto De Pesquisas Tecnológicas. Manual de gerenciamento integrado. Lixo Municipal. São Paulo. 2000.

12 ESIM, T. COSGUN, N. Study conducted to reduce construction waste generation in Turkey. Builing and Environmente, Vol. 42, p. 1667-1674, 2007.

13 ECHIMENCO, L. Pneus usados rendem lucros. Jornal O Estado de São Paulo. 17 abr. 2001.

14 CUNHA, I. O jogo da sustentabilidade. In: Encontro Nacional de Gestão Ambiental e Meio Ambiente - EMGEMA, 7, 2003, São Paulo. Anais... São Paulo: [s.n.], 2003. p. 1-20. Meio digital.

15 RECICLANIP. Construtora geral a homepage. Disponível em <htt://www.reciclanip.com.br $>$. Acesso em: 08 jan. 2015. 
16 RESCHNER, K.; 2008. Scrap Tire Recycling: A Summary of Prevalent Disposal and Recycling Methods. Retrieved from <www.entire-engineering $>$. Acesso em: 10 jan. 2015.

17 YUNPING XI, et al. Utilization of solid wastes (waste glass and rubber particles) as aggregates in concrete. In: International Workshop on Sustainable Development And Concrete Technology. pp.45-54, 2004.

18 KAMIMURA, E. Potencial dos resíduos de borracha de pneus pela indústria da construção civil. 2002. Dissertação de Mestrado em Engenharia Civil. Universidade Federal de Santa Catarina, Programa de Pós Graduação em Engenharia Civil. Florianópolis.

19 ABNT. Associação Brasileira de Normas Técnicas. NBR 5738. Moldagem e Cura de corpos-de-prova cilíndricos ou prismáticos de concreto. Rio de Janeiro. 2003.

20 ABNT. Associação Brasileira de Normas Técnicas. NBR 5739. Concreto Ensaio de compressão de corpos-de-prova cilíndricos. Rio de Janeiro. 2003.

21 ABNT. Associação Brasileira de Normas Técnicas. NBR 7211. Agregados para concretos - especificação. Rio de Janeiro. 2009.

22 BNT. Associação Brasileira de Normas Técnicas. NBR 9778._Absorção de Água por Índice de Vazios. Rio de Janeiro. 2009.

23 ABNT. Associação Brasileira de Normas Técnicas. NBR 9781. Peças de concreto para pavimentação (Especificações e metodologia de ensaio). Rio de Janeiro. 2003. 